\title{
Alcoholic liver disease and bilateral multifocal central serous retinopathy: a case report
}

\author{
Despoina Gkotsi ${ }^{1 *}$, Manish Gupta², Gerassimos Lascaratos ${ }^{3}$, Andreas Syrogiannis $^{3}$ and Baljean Dhillon ${ }^{3}$
}

\begin{abstract}
Introduction: We present a unique case of a patient with bilateral, multifocal central serous retinopathy in a patient with alcoholic liver disease.
\end{abstract}

Case presentation: A 58-year-old Caucasian man with alcoholic liver disease, liver cirrhosis and ascites presented to the eye clinic. The ophthalmoscopic examination of both eyes revealed a symmetrical pattern of variably sized, slightly yellowish, translucent, raised lesions throughout the fundi which were confirmed to be caused by multifocal central serous retinopathy after optical coherence tomography and autofluoresence tests.

Conclusion: This case highlights the possible link between central serous retinopathy and end-stage liver disease, with potential implications for the pathogenesis of central serous retinopathy in these patients.

Keywords: Alcoholic liver disease, Ascites, Central serous retinopathy

\section{Introduction}

Central serous retinopathy (CSR) is an exudative chorioretinopathy characterized by an exudative neurosensory retinal detachment with or without an associated detachment of the retinal pigment epithelium (RPE). It typically occurs in young, healthy adults and is usually idiopathic. The age range at the time of first diagnosis is generally from 22 to 83 years, and patients older than 50 years of age tend to have bilateral disease, systemic hypertension and a history of corticosteroid use [1]. Rare variants of CSR with chronic, bilateral, extrafoveal, multifocal and bullous retinal detachments have also been observed in patients undergoing cardiac transplantation [2]. Liver disease may be involved in sight-threatening eye diseases. The ophthalmic pathologies of cirrhosis in the literature include xerophthalmia, vitamin A deficiency and color blindness [3]. Abe et al. found retinopathy with hemorrhages and exudates in $31.8 \%$ of patients with hepatitis $\mathrm{C}$, irrespective of liver cirrhosis [4]. According to Onder et al., retinopathy can be present not only in hepatitis C-positive patients but also in patients with other causes of liver cirrhosis, and soft exudates may develop in cirrhotic patients, probably due to loss of the synthetic function of the liver and the hemodynamic effects of portal hypertension [3]. Haimovici et al. showed a

\footnotetext{
* Correspondence: despgotsi@yahoo.co.uk

${ }^{1}$ Institute of Ophthalmology, 11-43 Bath Street, London EC1V 9EL, UK

Full list of author information is available at the end of the article
}

statistically significant relationship between alcohol intake and CSR [5]. Experimental studies have shown serous retinal detachment secondary to alteration of choroidal vascular permeability [6]. One of the studies suggests that ischemia at the level of the choroid can cause capillary and venous congestion with increased fluid transudation [7]. We report a unique case of bilateral multifocal CSR secondary to alcoholic chronic liver disease in a 58-yearold man.

\section{Case presentation}

A 58-year-old Caucasian man was referred to the eye clinic in view of multiple raised yellowish lesions in both fundi. He had originally visited his optician for occasional flashes and floaters. He had recently been diagnosed with diet controlled type 2 diabetes mellitus and was on a low dose of amlodipine ( $5 \mathrm{mg} /$ day) for well controlled hypertension. His other drug history included analgesics (paracetamol, dihydrocodeine) and omeprazole. He admitted to heavy alcohol consumption in the past and had chronic liver disease with ascites.

His examination revealed that he had hepatomegaly with a palpable liver edge three fingerbreadths below the right costal margin, but no splenomegaly. An ultrasound of the liver showed generally increased echogenicity suggestive of liver cirrhosis. A computed tomography (CT) scan confirmed the presence of liver cirrhosis and 
showed evidence of esophageal varices, in keeping with decompensated chronic liver disease.

There was no evidence of a localized lesion in the liver, ruling out the possibility of both hepatocellular carcinoma and metastatic disease as causes of decompensation. His liver function tests (LFTs), including alkaline phosphatase (ALP), alanine aminotransferase (ALT) and $\gamma$-glutamyl transferase (GGT), had been elevated for several years. Interestingly, he was also found to have a marginally elevated plasma viscosity of $1.81 \mathrm{mPa} / \mathrm{s}$ (normal range 1.5 to $1.72 \mathrm{mPa} / \mathrm{s}$ ) with no evidence of paraprotein.

His ocular examination was within normal limits for the anterior segment. His visual acuity was $6 / 6$ in both eyes. Ophthalmoscopic examination of both eyes revealed a symmetrical pattern of dozens of variably sized, slightly yellowish, translucent raised lesions throughout the fundi (Figures 1A and 1B). These lesions were confirmed as multiple neurosensory retinal detachments on optical coherence tomography (OCT) (Figure 2) and fundus autofluorescence (Figures $3 \mathrm{~A}$ and $3 \mathrm{~B}$ ). The patient was followed-up in the eye clinic and was asymptomatic until his last follow-up. Visual acuity, fundus and OCT findings were unchanged. As the visual acuity was good and there was no evidence of choroidal neovascularization, conservative management was recommended.

\section{Discussion}

From a pathophysiological aspect, we hypothesize that in our patient the damaged liver produced less blood protein. This may have disturbed the body's fluid balance, leading to alteration of choroidal vascular permeability, increased fluid transudation, serous fluid accumulation in the neurosensory retina and thus multifocal CSR [6]. Ammonia dysmetabolism has also been noted in patients with liver cirrhosis. It is perhaps interesting to note that patients

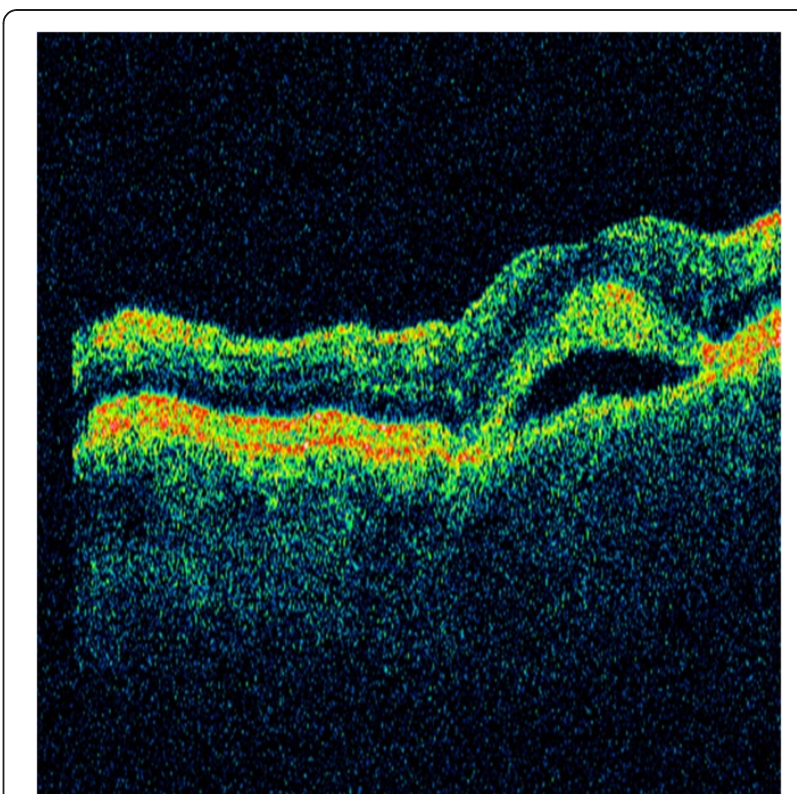

Figure 2 Optical coherence tomography image. Optical coherence tomography performed through the posterior pole demonstrated serous sensory detachment without any suggestion of retinal pigment epithelial detachment or retinal thinning. The image was obtained at presentation.

with minimal hepatic encephalopathy, despite their presenting with normal mental and neurological status upon clinical examination, have been found to demonstrate inflammation and raised levels of ammonia in the blood caused by diminished clearance by the liver [8]. The increased serum levels of inflammatory markers (such as C-reactive protein, white blood cell count and IL-6) found in patients with liver cirrhosis [8] have been implicated in the breakdown of the blood-brain barrier. IL-6 and TNF- $\alpha$ are known to enhance fluid-phase permeability of isolated brain endothelial cells in vitro [9], suggesting that
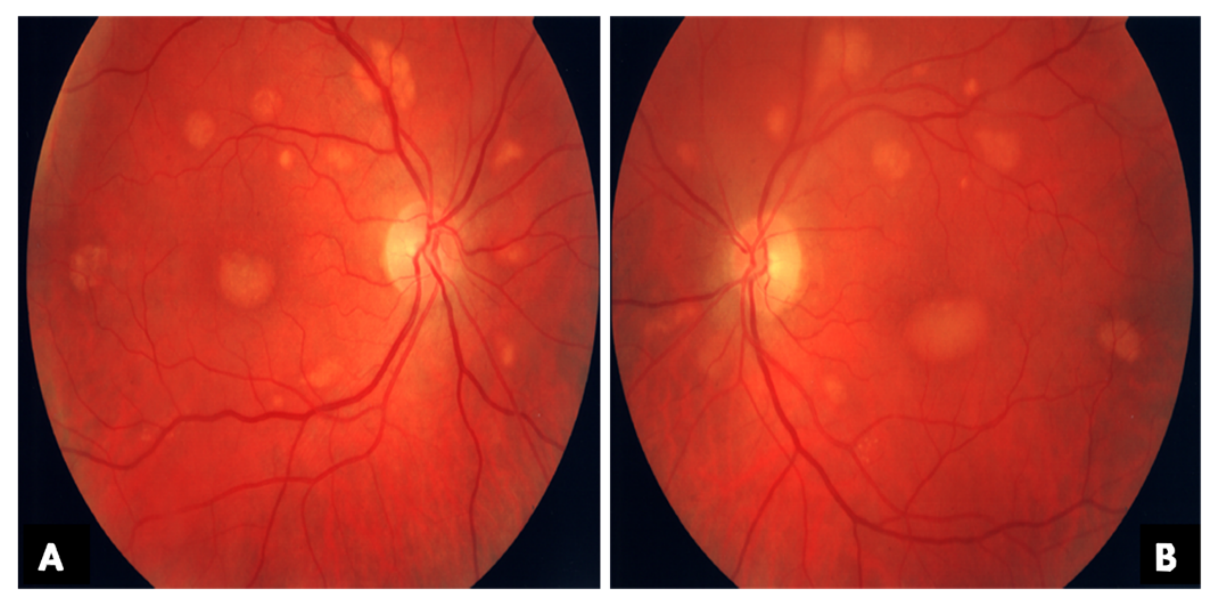

Figure 1 (A) and (B) Fundal images. Variably sized, slightly yellowish, translucent raised lesions throughout the fundi in both the right eye (A) and the left eye (B). Images were obtained at presentation. 

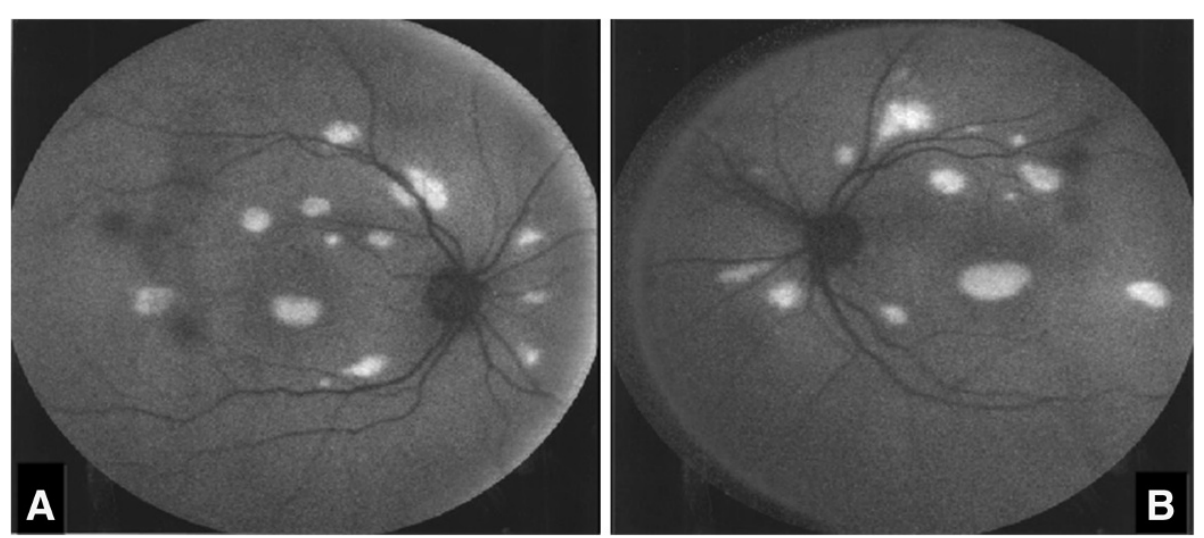

Figure 3 (A) and (B) Fundus autofluorescence images. Fundus autofluorescence recorded using a confocal scanning laser ophthalmoscope showed autofluorescence, which corresponds with the detached sensory retina in the right eye (A) and the left eye (B). The images were obtained at presentation.

these and other inflammatory markers could also potentially contribute to changes in the outer blood-retina barrier and to an increase in choroidal vascular permeability, leading to CSR. Moreover, alcohol has been shown to be associated with nitric oxide-related abnormalities of choroidal blood flow autoregulation [10], thus providing an additional mechanism for the change in choroidal vascular permeability and the associated fluid leakage in the subRPE space and CSR development. Oxidative stress has also been implicated in liver cirrhosis [11]. Enhanced production of reactive oxygen species is thought to be involved in the nitration of tyrosine residues in intracellular proteins, thus affecting transastrocytic substrate transport and selective degradation of the permeability of the blood-brain barrier and potentially the outer blood-retina barrier [12,13].

\section{Conclusion}

To the best of our knowledge, this is the first case of multifocal CSR related to alcoholic liver disease to be reported in the literature and has potential implications for the pathogenesis of CSR in these patients. Our patient had no other risk factors for CSR [5], such as systemic steroid, antihistamine or antibiotic use; history of autoimmune disease; untreated hypertension; or tobacco use. The differential diagnoses of acute exudative polymorphous paraneoplastic vitelliform maculopathy [14] and acute exudative polymorphous vitelliform maculopathy [15] could not be excluded in the absence of fluorescein angiography and electroretinography, although the non-progressive nature of the lesions during followup in our patient, the absence of subretinal yellowish deposits gravitating as a meniscus below the macula, and the normal visual acuity were not supportive of these diagnoses.

\section{Consent}

Written informed consent was obtained from the patient for publication of this case report and any accompanying images. A copy of the written consent is available for review by the Editor-in-Chief of this journal.

\section{Abbreviations}

ALP: Alkaline phosphatase; ALT: Alanine aminotransferase; CSR: Central serous retinopathy; CT: Computed tomography; GGT: $\gamma$-glutamyl transferase; IL: Interleukin; LFT: Liver function test; OCT: Optical coherence tomography; RPE: Retinal pigment epithelium; TNF: Tumor necrosis factor.

\section{Competing interests}

The authors declare that they have no competing interests.

\section{Authors' contributions}

DG conceived and wrote the manuscript. MG wrote and reviewed the manuscript and provided final approval of the manuscript for publication. GL reviewed the manuscript and collected the references with final approval. AS followed up the patient and reviewed the manuscript. BD suggested changes and gave final approval of the manuscript for publication. All authors read and approved the final manuscript.

\section{Author details}

${ }^{1}$ Institute of Ophthalmology, 11-43 Bath Street, London EC1V 9EL, UK. ${ }^{2} \mathrm{NHS}$ Greater Glasgow and Clyde, Stobhill and Gartnavel Hospital, 1053 Great Western Road, Glasgow G12 OYN, UK. ${ }^{3}$ Princess Alexandra Eye Pavilion, Edinburgh EH3 9HA, UK.

Received: 4 June 2012 Accepted: 28 November 2012 Published: 13 February 2013

\section{References}

1. Spaide RF, Campeas L, Haas A, Yannuzzi LA, Fisher YL, Guyer DR, Slakter JS, Sorenson JA, Orlock DA: Central serous chorioretinopathy in younger and older adults. Ophthalmology 1996, 103:2070-2080.

2. Friberg TR, Eller AW: Serous retinal detachment resembling central serous chorioretinopathy following organ transplantation. Graefes Arch Clin Exp Ophthalmol 1990, 228:305-309.

3. Onder C, Bengur T, Selcuk D, Bulent S, Belkis U, Ahmet M, Eser P, Leyla AS: Relationship between retinopathy and cirrhosis. World J Gastroenterol 2005, 11:2193-2196.

4. Abe T, Nakajima A, Satoh N, Koizumi T, Sakuragi S, Ono T, Komatsu M, Masamune O: Clinical characteristics of hepatitis C virus-associated retinopathy. Jpn J Ophthalmol 1995, 39:411-419. 
5. Haimovici R, Koh S, Gagnon DR, Lehrfeld T, Wellik S: Central Serous Chorioretinopathy Case-Control Study Group. Risk factors for central serous chorioretinopathy: a case-control study. Ophthalmology 2004, 111:244-249.

6. Chon $\mathrm{CH}$, Yao XY, Dalal R, Takeuchi A, Kim RY, Marmor MF: An experimental model of retinal pigment epithelial and neurosensory serous detachment. Retina 1996, 16:139-144.

7. Prünte $C$, Flammer J: Choroidal capillary and venous congestion in central serous chorioretinopathy. Am J Ophthalmol 1996, 121:26-34.

8. Shawcross DL, Wright G, Olde Damink SW, Jalan R: Role of ammonia and inflammation in minimal hepatic encephalopathy. Metab Brain Dis 2007, 22:125-138.

9. Duchini A, Govindarajan S, Santucci M, Zampi G, Hofman FM: Effects of tumor necrosis factor-

.alpha; and interleukin-6 on fluid-phase permeability and ammonia diffusion in CNS-derived endothelial cells. J Investig Med 1996, 44:474-482.

10. Tittl MK, Spaide RF, Wong D, Pilotto E, Yannuzzi LA, Fisher YL, Freund B, Guyer DR, Slakter JS, Sorenson JA: Systemic findings associated with central serous chorioretinopathy. Am J Ophthalmol 1999, 128:63-68.

11. Wu D, Cederbaum Al: Oxidative stress and alcoholic liver disease. Semin Liver Dis 2009, 29:141-154.

12. Murthy CR, Rama Rao KV, Bai G, Norenberg MD: Ammonia-induced production of free radicals in primary cultures of rat astrocytes. J Neurosci Res 2001, 66:282-288.

13. Häussinger D, Schliess F: Pathogenetic mechanisms of hepatic encephalopathy. Gut 2008, 57:1156-1165

14. Grunwald L, Kligman BE, Shields CL: Acute exudative polymorphous paraneoplastic vitelliform maculopathy in a patient with carcinoma, not melanoma. Arch Ophthalmol 2011, 129:1104-1106.

15. Chan CK, Gass JD, Lin SG: Acute exudative polymorphous vitelliform maculopathy syndrome. Retina 2003, 23:453-462.

doi:10.1186/1752-1947-7-43

Cite this article as: Gkotsi et al:: Alcoholic liver disease and bilateral multifocal central serous retinopathy: a case report. Journal of Medical Case Reports 2013 7:43.

\section{Submit your next manuscript to BioMed Central and take full advantage of:}

- Convenient online submission

- Thorough peer review

- No space constraints or color figure charges

- Immediate publication on acceptance

- Inclusion in PubMed, CAS, Scopus and Google Scholar

- Research which is freely available for redistribution 